\title{
Mulheres que superaram o Câncer: À volta ao mercado de trabalho
}

\author{
Women Who Overcame Cancer: Back to the Job Market \\ Daniele Ramos Guedes $^{1^{*} \bullet}$, Glenda da Silva Coutinho ${ }^{2} \bullet$, Josiana Alves Pimentel ${ }^{3} \bullet$

\begin{abstract}
${ }^{1}$ Mestranda do Curso de Gestão e Saúde Pública, Universidad Columbia Del Paraguai, Asunción, Paraguai, Docente Instituto Superior, Macapá, Amapá, Brasil. ${ }^{3}$ Bacharel em Serviço Social, Instituto Macapaense de Melhor Ensino Superior, Macapá, Amapá, Brasil. *Autor para correspondência. E-mail: glendactnh@gmail.com
\end{abstract} \\ Macapaense de Melhor Ensino Superior, Macapá, Amapá, Brasil. Bacharel em Serviço Social, Instituto Macapaense de Melhor Ensino
}

\begin{abstract}
Resumo: Introdução: Sabe-se que o câncer é uma das doenças que mais causam mortes no mundo, além do afastamento do trabalho e em muitos casos o desligamento, podendo ser classificado maligno quando o crescimento desordenado dessas células é incontrolável, em grande quantidade e agressivo, o que deixa a pessoa debilitada e, em grande parte dos casos, traz risco de morte a curto, médio ou longo prazo, conforme as condições clínicas e avanço da doença em cada situação. Para elaboração do referencial teórico realizouse uma pesquisa bibliográfica, referente ao estudo sobre a doença câncer, sua história e principalmente os impactos que a doença e o tratamento têm na vida da mulher, bem como a volta ao mercado de trabalho após ter vencido a doença e seu controle. Desta forma, conforme os resultados adquiridos nos dados documentais, por meio da busca de artigos científicos, em bases de dados eletrônicos no Google Acadêmico, Scielo, foram selecionadas as referências mais importantes para o desenvolvimento do trabalho.
\end{abstract}

Palavras-chave: câncer, mulher, trabalho, mercado.

\begin{abstract}
Introduction: It is known that cancer is one of the diseases that cause the most deaths in the world, in addition to being away from work and, in many cases, dismissal, and can be classified as malignant when the disordered growth of these cells is uncontrollable, in large quantities and aggressive, leaves the person weakened and, in most cases, carries a risk of death in the short, medium or long term, depending on the clinical conditions and progression of the disease in each situation. To elaborate the theoretical framework, a bibliographic research was carried out, referring to the study about the cancer disease, its history and mainly the impacts that the disease and the treatment have on the woman's life, as well as the return to the job market after having won the disease and its control. Thus, according to the results acquired in the documentary data, through the search for scientific articles, in electronic databases in Google Scholar, Scielo, the most important references for the development of the work were selected.
\end{abstract}

Keywords: cancer, women, work, Marketplace.

\section{Introdução}

O câncer é uma das doenças que mais cresce na atualidade, entre as mulheres, é o mais recorrente, seu tratamento além de caro impossibilita o paciente a trabalhar, obrigando assim muitos a deixarem seu emprego para dedicar-se de forma exclusiva ao tratamento, muitas vezes longo e severo. Assim o objetivo geral, investigar através de artigos, notícias, reportagens e outros as mulheres que superaram o câncer e que enfrentam o desafio da inserção à volta ao mercado de trabalho.

Ao observar a lacuna existente entre a luta para vencer o câncer e se readaptar novamente a vida profissional e social, bem como seu retorno ao cotidiano do trabalho, e a forma como retornar ao convívio social. Assim buscou-se o seguinte questionamento: Quais as dificuldades que as mulheres encontram ao retornar para o mercado de trabalho?

Para elaboração do referencial teórico realizou-se uma pesquisa bibliográfica, por meio de uma abordagem qualitativa, referente o estudo sobre a doença câncer, sua história e principalmente os impactos que a doença e o tratamento têm na vida da mulher, bem como a volta ao mercado de trabalho após ter vencido a doença e seu controle. 


\section{Revisão}

\section{Conceituar câncer: epidemiologia da doença}

Todos nós somos formados por células que se organizam em tecidos e órgãos, as células normais se dividem, amadurecem e morrem, renovando-se a cada ciclo. $O$ câncer se desenvolve quando células anormais deixam de seguir esse processo natural, sofrendo mutação que pode provocar danos em um ou mais genes de uma única célula.

A palavra câncer vem do grego karkínos, que quer dizer caranguejo, e foi utilizada pela primeira vez por Hipócrates, o pai da medicina, que viveu entre 460 e 377 A.C. O câncer não é uma doença nova. O fato de ter sido detectado em múmias egípcias comprova que ele já comprometia o homem há mais de 3 mil anos antes de Cristo. Atualmente, câncer é o nome geral dado a um conjunto de mais de 100 doenças, que têm em comum o crescimento desordenado de células, que tendem a invadir tecidos e órgãos vizinhos.

Seguindo essa linha de raciocínio Torres (2003) destaca que o homem, geralmente, expressa em símbolos as ameaças à vida, o câncer suscita a ideia de um caranguejo animal que vive em profundidade, invisível e se desloca mal coordenado e imprevisível; é agressivo, apodera-se de suas presas e a tortura até à morte.

O câncer é uma palavra que define diversas doenças e exige diferentes respostas de prevenção assim como diagnóstico e terapias, no Brasil vêm apresentando dados alarmantes de casos de câncer causando preocupação quando refletimos sobre a saúde pública. O índice de diagnósticos tem aumentado de forma importante nos últimos anos o que influência na economia e causa impacto no desenvolvimento do país, pois causa perda de produtividade devido aos adoecimentos, mortes, aposentadorias precoces e pensões, Torres (2003).

Uma em cada cinco pessoas no mundo irá contrair câncer em algum momento de sua vida, diante dos numerosos tipos de câncer, diversos são os registros epidemiológicos entre a população mundial, e brasileira especificamente. Desta forma, classifica o câncer como uma variedade de doenças, com localizações e aspectos biológicos múltiplos, que causam diferentes sintomas e tratamentos além de ser uma das doenças que mais causa mortes no mundo (Brasil, 2011).

O câncer pode afetar várias partes do corpo, um termo geral para um grande número de doenças em que as células do corpo se multiplicam descontroladamente células normais se dividem e se multiplicam assim o corpo pode formar novas células ou repor velhas ou danificadas. Quando o câncer ocorre, a divisão celular se torna irrestrita, quando não há necessidade para essa divisão, além disso, as células que se formam têm um formato irregular e não podem funcionar adequadamente (Silva, 2014).

Segundo autor Arendt (2007) essas células podem se formar numa massa sólida, chamada tumor benigno, somente tumor maligno é chamado de câncer. Tumores malignos tem uma tendência de se espalharem para outras partes do corpo. Isso ocorre porque as células tumorosas se separam do tumor e se espalham através da corrente sanguínea ou canais linfáticos, as células tumorosas formam um novo tumor numa outra parte do corpo chamada de uma metástase.

O que causa o câncer é desconhecido, mas a certos fatores de riscos que aumentam as chances de se contrair câncer, como tabagismo, alto consumo alcoólico, excessiva exposição ao sol, hereditariedade quando a pessoa nasce com uma mutação que faz com que ela tenha uma predisposição ao câncer e também podem ser desencadeados por agentes presentes no ambiente e na dieta que são chamados carcinógenos (Arendt, 2007).

Em relação à idade, algumas mulheres têm maior risco para o desenvolvimento desta doença, devido à exposição ao longo da vida e as alterações biológicas que acontece com o envelhecimento, aumentando ainda mais o risco de adquirir tal doença (Silva, Albuquerque, \& Leite, 2010).

O câncer nem sempre pode ser curado, um tratamento de sucesso depende da sua localização, tipo, tamanho da área de afetada e a proporção do crescimento do câncer. Geralmente é tratado com uma combinação de cirurgia, quimioterapia e radioterapia, isso diferencia de acordo com o paciente e o tipo da doença. Segundo dados do INCA (2018), sobre o Estado do Amapá, a estimativa em 2018 mostrou que os cinco tumores mais incidentes para o sexo masculino eram o câncer de pele não melanoma (40 casos novos), próstata (90), Traqueia , Brônquio e Pulmão (30), cólon e reto (20) e estômago (60). Para o sexo feminino, destacavam-se, entre os cinco mais incidentes, os tumores de colo do útero (110), mama (60), pele não melanoma (20 casos novos), Estômago (20) e pulmão (20).

Segundo o Instituto Oncoguia (2015) os genes são segmentos do DNA - siga em inglês para ácido desoxirribonucléico , o reservatório das moléculas de informação genética - que controlam as funções normais das células, quando danificada, a célula se divide descontroladamente e produz novas células anormais. Falham-se os sistemas de reparo e imunológico na tarefa de destruir e limitar essas células anormais, as novas vão se tornando cada vez mais anormais, eventualmente produzindo células cancerosas. 
Câncer é o crescimento desordenado de células que invadem órgãos e tecidos, essas células doentes podem espalhar-se para outras regiões, o que conhecemos como metástase. Atualmente, existe mais de cem tipos de câncer na literatura médica mundial (Teixeira, 2009).

As células cancerosas se dividem mais rapidamente do que as normais e geralmente são bem desorganizadas, com o tempo, podem se empilhar umas sobre as outras, formando uma massa de tecido chamada tumor. Todo esse processo, em que uma célula normalmente se torna um tumor maligno ou câncer, pode levar muitos anos. O termo "estágio" é usado para descrever a extensão ou a gravidade do câncer, no estágio inicial, a pessoa tem apenas um pequeno tumor maligno, no avançado, o tumor, maior, já pode ter se espalhado para as áreas próximas (linfonodos) ou outras partes do corpo (metástases). Para determinar a chance de cura do câncer (prognóstico), os médicos consideram vários fatores, inclusive o tipo e o estágio do câncer (Teixeira, 2009).

Segundo INCA (2018) há vários tipos de câncer por isso, a doença pode evoluir de diferentes formas, alguns tipos têm desenvolvimento rápido, enquanto outros crescem mais lentamente, esses comportamentos distintos se devem a características próprias de cada tumor.

$\mathrm{O}$ organismo humano encontra-se exposto a múltiplos fatores carcinogênicos , com efeitos aditivos ou multiplicativos. Sabe-se que a predisposição individual tem um papel decisivo na resposta final, porém não é possível definir em que grau ela influencia a relação entre a dose e o tempo de exposição ao carcinógeno e a resposta individual à exposição. Os principais fatores de risco são tabagismo, alimentação não saudável, sobre peso, ingestão de bebidas alcoólicas, radiação, infecções, exposição solar e sedentarismo também estão relacionados ao câncer (Silva, 2014).

O instituto Nacional do Câncer frisa ainda que o baixo consumo de frutas, legumes e verduras está entre os dez principais fatores de risco associados à ocorrência de doenças crônicas não transmissíveis, por isso o incentivo ao consumo desses alimentos tem sido priorizado.

Muitos outros fatores presentes no meio ambiente, e estilo de vida podem causar ou prevenir o câncer, como o envelhecimento que traz mudanças nas células que aumentam as chances de câncer. Esse fator somado ao fato de as células das pessoas idosas terem sido expostas por mais tempo aos diferentes fatores de risco para câncer, explica em parte o porquê de o câncer ser mais frequente nesses indivíduos (Teixeira, 2009).

Os fatores genéticos e hereditários estão relacionados às mutações que ocorre em determinados genes, existem vários casos de mulheres que possuem câncer de mama ou câncer de ovário em parentes consanguíneos, sobretudo em idade jovem. Câncer pode ser classificado em maligno quando o crescimento desordenado dessas células é incontrolável, em grande quantidade e agressivo, o que deixa a pessoa debilitada e, em grande parte dos casos, traz risco de morte a curto, médio ou longo prazo, conforme as condições clínicas e avanço da doença em cada situação, e o câncer é benigno quando essas células desordenadas crescem em apenas um local específico do corpo, de forma devagar, e trazem semelhanças aos tecidos originais, esse tipo de câncer raramente constitui risco de morte (Silva, 2014).

O tratamento do câncer é feito por meio de uma ou de várias modalidades e técnicas de tratamento combinadas, a principal delas é a cirurgia oncológica, que pode ser empregada em conjunto com radioterapia, quimioterapia ou transplante de medula óssea, conforme cada caso. O médico vai escolher o tratamento mais adequado de acordo com a localização, o tipo do câncer, a condição clínica do paciente e a extensão da doença.

Para Cestari e Carlotto (2012), o câncer deixou de ser uma sentença de morte certa nas últimas décadas hoje é uma doença que tem tratamento e tem cura, tratamento do câncer exige da paciente uma série de adaptações em sua rotina. Depois de concluído, ela pode retomar a sua vida, mas nem sempre esse é um processo simples. Baseado na experiência de mulheres que já passaram por isso, a doença é cada vez mais tratada como crônica o que permite ao paciente ter maior tempo de vida e bem-estar, podendo trabalhar e exercer suas funções.

\section{Pacientes com Câncer}

Todos os dias indivíduos de todo mundo são atingidos por doenças crônicas como, diabetes, hipertensão, asma entre outras que mudam a rotina e acarretam alterações nas suas vidas e de seus familiares de diferentes maneiras. O mesmo acontece com paciente atingido pelo câncer o diagnóstico muda sua vida e traz diversas mudanças tanto físicas como psicológicas. Combater um câncer é uma batalha e tanto, mas em momentos difíceis é preciso manter a calma e procurar a melhor direção, além da angústia com a saúde, surgem também os problemas financeiros, já que a doença muitas vezes pede tratamentos em outras cidades, consultas com especialistas, exames, uso de medicamentos caros e, muitas vezes, afastamento do trabalho (Imbuzeiro, 2015). 
A incidência do câncer cresce no Brasil, como em todo o mundo, num ritmo que acompanha o envelhecimento populacional decorrente do aumento da expectativa de vida. É um resultado direto das grandes transformações globais das últimas décadas, que alteraram a situação de saúde dos povos pela urbanização acelerada, novos modos de vida, novos padrões de consumo (Imbuzeiro, 2015).

Porém, diferente das doenças crônicas citadas no primeiro parágrafo o câncer representa em primeiro momento um ponto final, o que afeta o modo como o paciente a partir do diagnóstico vai encarar o tratamento. Vale ressaltar que as perspectivas de vida e cura para pacientes com câncer melhoraram muito por causa do avanço da ciência e da tecnologia. No entanto, em consequência da doença oculta ou das várias modalidades de tratamento, os pacientes com câncer podem experimentar diversos problemas secundários, como infecção, contagens de leucócitos reduzidas, sangramento, problemas cutâneos, problemas nutricionais, dor, fadiga e estresse psicológico (Smeltzer et al., 2012).

Para o paciente, o câncer traz em si a consciência da possibilidade de morte, essa ideia vem acompanhada de angústia e temores que perpassam o desenrolar do tratamento, o medo é a resposta psicológica mais comum diante da morte, o medo de morrer é universal e atingem todos os seres humanos (Kovács, 2002).

De acordo com o Instituto Nacional do Câncer (Silva, 2014) o câncer traz mudanças efetivas na vida da pessoa, porque o diagnóstico altera a condição anteriormente estabelecida de atividade para coloca-la num lugar de passividade em relação à vida. Por esses e outros motivos, é muito importante que um tempo seja fornecido ao paciente e à família para que possam lidar com o diagnóstico.

As perspectivas para pacientes com câncer melhoraram muito por causa dos avanços científicos e tecnológicos, no entanto, em consequência da doença subjacente ou das várias modalidades de tratamento, os pacientes com câncer podem não desempenhar suas atividades laborais como antes da doença o que pode acarretar no afastamento do trabalho ou até mesmo na demissão. (Borges et al., 2006).

Devem ser criados espaços onde o acesso à informação, o apoio mútuo, a troca de experiências de motivação, a vivência de situações crie oportunidades para pacientes e profissionais de saúde tirar dúvidas, interagir e superar as dificuldades no processo de tratamento e por que não do retorno ao ambiente profissional, como forma de estimular o paciente ao tratamento, a vida futura e retorno ao ambiente profissional. De uma forma geral, é muito importante essa volta para a pessoa se sentir ativa, ter espaço para se desenvolver e seguir a vida da forma mais normal possível (Mendes et al., 2008).

Ser reinserida no mercado de trabalho é essencial para a mulher não somente pela manutenção financeira como também pela realização pessoal, uma vez que a doença impossibilitou o desempenho de suas funções e a conduziu a posição de excluído. Do ponto de vista de Mendes et al. (2008):

O diagnóstico de câncer é vivenciado como um momento de imensa angústia, sofrimento e ansiedade, durante o tratamento, a paciente vivencia perdas, por exemplo, físicas e financeiras, e sintomas adversos, tais como: depressão e diminuição da autoestima, sendo necessárias constantes adaptações às mudanças físicas, psicológicas, sociais, familiares e emocionais ocorridas devido a doença. Segundo Penna (2004): "estas consequências se devem porque a palavra câncer adquiriu uma conotação de doença terrível, sem cura, e que termina em morte sofrida”

Seguindo essa linha de raciocínio Prado (2002) expressa que a mastectomia pode provocar consequências importantes na vida da mulher em razão das modificações estéticas decorrentes, e assim, desencadear novas reações relacionadas ao próprio corpo e às demais pessoas. Um dos principais fatores que influenciam na imagem corporal da mulher é caracterizado pelos parâmetros que a sociedade impõe para a identificação do corpo perfeito, do corpo feminino.

A sociedade impõe um padrão, e isso se torna devastador principalmente para aquelas mulheres vítimas de câncer submetidas a cirurgias que mudam o modo como elas enxergam o próprio corpo (Prado, 2002).

\section{Qualidade de vida após a cura}

O impacto do diagnóstico do câncer geralmente implica em angústia, insegurança e preocupação com o prognóstico da doença e suas repercussões físicas, sociais e psicológicas, que abarcam a possibilidade ou não de sobrevida. A qualidade de vida diminui em mulheres com baixo nível de escolaridade já que o nível de escolaridade influencia a qualidade de vida, outra comorbidade, que utilizam medicamentos ansiolíticos, que tiveram gravidezes anteriores e naquelas com retração do mamilo (Villar et al., 2017)

A autora ainda continua dizendo que não é surpreendente que tanto o tratamento cirúrgico quanto a própria doença tenham um impacto devastador na confiança e na autoestima das mulheres, fazendo com que elas se sintam menos atraentes do que antes, diminuindo as pontuações da imagem corporal e afetando negativamente sua sexualidade. 
O diagnóstico de câncer é vivenciado como um momento de imensa angústia, sofrimento e ansiedade, durante o tratamento, a paciente vivencia perdas, por exemplo, físicas e financeiras, e sintomas adversos, tais como: depressão e diminuição da autoestima, sendo necessárias constantes adaptações às mudanças físicas, psicológicas, sociais, familiares e emocionais ocorridas (Coelho, 2015).

Á qualidade de vida dos pacientes oncológicos compreende-se que a atividade foi o domínio mais afetado nos pacientes, entretanto, ao realizar as atividades novamente gera uma satisfação e sensação de bem-estar, que pode ser considerando qualidade de vida (Backer et al., 2007).

A ansiedade foi o que mais afetou os pacientes oncológicos devido ao tratamento, o medo e o anseio de saber qual seria o diagnóstico do câncer, apesar dos avanços científicos, o câncer ainda está associado ao sofrimento e à morte. A ansiedade e o diagnóstico do câncer permanecem juntos, portanto, o diagnóstico dá início a uma variedade sensações (Vasconcelos, Costa, \& Barbosa, 2008).

Os níveis de ansiedade caracterizado preocupação e como traço melhoraram significativamente após a conclusão dos tratamentos. A vida social é extremamente afetada devido os sintomas decorrentes ao tratamento, tais como náuseas, dores, fraqueza, a maioria das pacientes relatam falta de ânimo para realizar atividades sociais ou lazer devido ao incomodo ocasionado pelos sintomas da doença, estes sintomas interrompem a realização de atividades prazerosas que os pacientes costumavam realizar antes da doença (Costa Neto \& Araújo, 2001).

A qualidade de vida das mulheres tratadas de câncer sofre maior influência dos domínios físico e psicológicos. De fato, quanto maiores os danos físicos e psicológicos causados pela doença e pelo tratamento, pior a qualidade de vida dessas mulheres (Costa Neto \& Araújo, 2001).

\section{A inserção e a discriminação da mulher com câncer no mercado de trabalho.}

Além de afetar o indivíduo e sua família, o câncer afeta toda a sociedade, pois acarreta na redução do potencial de trabalho humano e impacto econômico resultante dos elevados custos envolvidos com assistência à saúde, poluição, degradação ambiental, pesquisa e educação. No entanto existem ainda perdas incalculáveis como a dor, o sofrimento do doente e da família (Feitosa \& Pontes, 2011).

Os autores ainda destacam que existem muitas mulheres fora do mercado e que trabalham cuidando dos filhos e da casa, mas é crescente a quantidade de profissionais do sexo feminino que estão disputando, em condições de igualdade e, muitas vezes de superioridade, em um determinado espaço no campo social, econômico e político. $\mathrm{O}$ que denota uma postura atuante, não apenas pelos seus próprios esforços, mas também pelas exigências do mundo moderno, que obrigou os homens a abrirem mão de sua atitude dominadora e caminharem no sentido de uma parceria necessária e enriquecedora.

Para Souza-Lobo (1991) a competência direcionada a mulher pode ser examinado a partir do ponto de vista que permite pensar essa noção a partir de uma perspectiva feminista. As definições de competência estão sempre direcionadas a características masculinas: criatividade, responsabilidade, iniciativa, capacidades técnicas e autonomia no trabalho, as mulheres raramente estão presentes em cargos que requerem tais características.

Segundo Hirata (2014), quando as mulheres possuem tais competências, elas são menos remuneradas. Aliás, a diferença salarial entre homens e mulheres é um fato no mundo inteiro. A autora ainda destaca questões fundamentais, como a competências em "relação a serviço", não são consideradas competências, mas atributo natural das mulheres, para as mulheres, é central avançar no reconhecimento de que as diferenças são culturais e de que a organização dos movimentos sociais.

Na visão de Muzart (2003) as mulheres chegam ao mercado de trabalho com suas habilidades limitadas marcadas pelo gênero. Além da naturalização de suas qualificações, existem várias explicações para que estas profissões sejam tão mal remuneradas.

Uma das explicações que o autor destaca é a de que o valor do trabalho não é intrínseco a ele, mas relacionado ao reconhecimento social, a definição de trabalho leve e trabalho pesado para tarefas similares, sendo leve sempre o que é realizado por mulheres, e, pesado, por homens (Muzart, 2003).

Existem vários fatores que podem estar ainda associados ao retorno ao trabalho, como, idade; raça; baixa renda familiar; baixa escolaridade; percepção do estado de saúde principalmente antes de receber o diagnóstico do câncer; o sentimento de discriminação causado pelos empregadores devido ao diagnóstico da doença (Paulilo, 1987).

A inserção das mulheres no mercado de trabalho, apesar de parecer estável, não é assim tão simples, surgem vários problemas enfrentados pelas mesmas no mundo todo, como: salário menor do que o do homem; dupla jornada; deficiências nas políticas sociais; menores chances de capacitação profissional; falta de voz nos espaços de decisão e de poder para negociar acordos coletivos de trabalho (Gomes, 2005). 
Antigamente as mulheres preferiam ter comportamentos masculinos nas empresas para poder ser reconhecida e respeitada no mercado de trabalho, mas com o tempo ficou claro que a diferença está no perfil feminino e sua forma de preocupação com o indivíduo (Silva, 2008).

A participação das mulheres nas organizações cresceu gradativamente, principalmente nas áreas de finanças, gerências e diretoria, as mulheres no setor executivo têm mostrado um grande potencial, resultando na demanda de cargos de liderança, quando falamos em igualdade entre homens e as mulheres, mostra-se que os direitos devem ser iguais, assim como as oportunidades (Machado, 2013).

É importante lembrar que o crescimento das mulheres no mercado de trabalho acaba sendo dificultado pelo simples fato de se "mulher", pois, muitas empresas acabam tornam difícil que a mulher consiga conciliar a vida profissional e pessoal, através de metas, exigindo dedicação quase que total à empresa, ou seja, e preciso provar que é capaz de cumprir aquela demanda, se dedicando ao máximo e esquecendo a vida pessoal (Galvão, 2008).

E possível perceber que os homens prevalecem predominantes nas atividades empresariais, quanto as mulheres em serviços domésticos, entretanto, por mais que a mulheres apresentem uma menor participação do que os homens, nota-se que de 2003 para 2015, elas ganharam participação em todos os grupamentos, exceto o de indústria, (IBGE, 2010).

A maioria das justificativas das empresas para contratação de mulheres é a força muscular, pois, justifica-se que as mesmas não possuem força suficiente para os trabalhos pesados como carregamentos de cargas, manuseio de cargas pesadas, entre outros. Entretanto, somente esse motivo não pode ser considerado para desmerecer o trabalho das mulheres, vistos que cada vez mais as inovações tecnológicas exigem cada vez menos esforço físico. (IPEA, 2011).

Hoje a responsabilidade de ajudar no sustento da família passou a ser divido entre homens e mulheres assim como os espaços profissionais, pois, o ensino e qualificação passaram a ser ofertado e garantido por lei. (OST, 2009).

As mulheres ao longo da tiveram transformações em sua vida familiar e na sociedade. Após séculos de trabalhos desqualificado, até os dias atuais, quando ainda é julgada no mercado de trabalho, hoje as mulheres não deixam de lutar por seus ideais e para garantia de seus direitos (Sina, 2005).

Ainda destaca que as transformações foram de extrema importância para á historia da mulher na sociedade, entretanto, as principais ocorreram em sua posição na sociedade, deixando de apenas subordinadas a tarefas do lar, filhos e marido, para assumir cargos políticos, em empresas, buscando o direito trabalhar e ter sua independência financeira (Braz, 2016).

\section{Discussão}

Durante o processo metodológico (levantamento bibliográfico, coleta e análise de dados) procurou-se produzir uma abordagem crítica para que pudessem ser visualizadas as contradições presentes nas situações ocorridas na instituição, em consonância com os objetivos propostos pela pesquisa, fundamentando-se no referencial teórico em tela.

Por meio da abordagem qualitativa a partir de estudo exploratório, para investigar as Mulheres que superaram o câncer que enfrentam o desafio da inserção à volta ao mercado de trabalho. A revisão bibliográfica sistemática da literatura, assim para Severino (2007) uma boa revisão apresenta o estado da arte sobre um tema, contribuindo para o desenvolvimento de teorias. A partir dos dados que foram levantados, concluímos que devido ao tratamento, geralmente, as pessoas que recebem o diagnóstico de câncer acabam se afastando de seu ambiente de trabalho, de como a doença e o tratamento ao qual são submetidos podem gerar limitações físicas e psicológicas, podem afetar o processo de retorno ao trabalho. As buscas por legislação e documentos oficiais e artigos científicos foram realizadas nas bases de dados eletrônicos Scielo, selecionados artigos em português, cuja publicação se dará entre 2014 a 2019.

A pesquisa qualitativa tem caráter exploratório: estimulam os entrevistados a pensar e falar livremente sobre algum tema, objeto ou conceito. Elas fazem emergir aspectos subjetivos, atingem motivações não explícitas, ou mesmo não conscientes, de forma espontânea (Bogdan \& Biklen, 2003).

Como critérios de Inclusão, foram incluídas no estudo artigos para dar embasamento ao tema. E critérios de Exclusão, foram excluídas no estudo artigos que não faz parte da temática.

Para atender os objetivos deste estudo, realizou-se uma vasta pesquisa bibliográfica, complementado por vários autores deram embasamento teórico e metodológico.

A revisão bibliográfica objetivou a descrição dos aspectos teóricos sobre o tema em estudo. De forma sistemática, esta pesquisa bibliográfica se dará com o fichamento de cada obra consultada, buscando-se 
ressaltar as ideias centrais expostas pelos autores, com ênfase no tema de interesse do estudo que estavam coerentes com os objetivos propostos.

A busca resultou em 60 artigos sobre Mulheres que superaram o Câncer, à volta ao mercado de trabalho, foram escolhidos 25 , os quais obedeceram integralmente aos critérios de busca estabelecidos: publicação em língua portuguesa entre os anos de 2014 a 2019, que tinham relação com a temática.

Durante o processo metodológico (levantamento bibliográfico, coleta e análise de dados) procurou-se produzir uma abordagem crítica para que pudessem ser visualizadas as contradições presentes nas situações ocorridas na instituição, em consonância com os objetivos propostos pela pesquisa, fundamentando-se no referencial teórico em tela.

\section{Considerações finais}

Esta pesquisa investigou-se as Mulheres que superaram o câncer e que enfrentam o desafio da inserção à volta ao mercado de trabalho. Baseou-se no referencial teórico, com dimensão teórico metodológico de vários autores que deram suporte na literatura deste estudo e nos dados obtidos na análise realizada, visando alcançar o objetivo de caracterizar a percepção das mulheres que tiveram câncer quanto ao seu processo de retorno ao trabalho, por meio da identificação das dificuldades encontradas por essas mulheres.

Percebe-se que o câncer emerge como uma doença de importância cada vez maior em todas as partes do mundo. O câncer é considerado um grave problema de saúde pública mundial, não só pelo número de casos crescentes diagnosticados a cada ano.

É preciso compreender que a vida dessas mulheres após o câncer e o retorno ao mercado de trabalho envolve um processo de adaptação, além do afastamento das atividades laborais interferindo principalmente no emocional dessas mulheres.

Almeja-se que o conhecimento proporcionado por esta pesquisa permita ampliar a compreensão da dificuldade que as mulheres que superaram o câncer possuem ao retornaram ao mercado de trabalho. Sendo assim, este estudo pode somar aos conhecimentos produzidos em relação ao processo de retorno destas mulheres ao mercado de trabalho e os impactos que o câncer pode afetar no âmbito profissional. Podendo demonstrar, ainda, a necessidade de planejar o retorno dessas mulheres com profissionais competentes para auxiliar neste planejamento visando à singularidade, segurança, saúde e qualidade de vida dessas mulheres.

Baseado na afirmação da hipótese onde o trabalho possui um papel importante na vida da mulher, garantindo muito mais do que sua subsistência, garante também sua independência.

\section{Referências}

Arendt, H. 2007. A condição humana (10a ed.). Rio de Janeiro, RJ: Forense Universitária.

Backer, I. C., Van Breda, E., Vreugdenhil, A., Nijziel, M. R., Kester, A. D., \& Schep, G. 2007. High-intensity strength training improves quality of life in cancer survivors. Acta Oncologica, 46(8), 1143-1151.

Bogdan, R. C., \& Biklen, S. K. 2003. Investigação qualitativa. Porto, PT: Porto Editora.

Borges, A. D. V. S., Silva, E. F. D., Mazer, S. M., Toniollo, P. B., Valle, E. R. M. D., \& Santos, M. A. D. 2006. Percepção da morte pelo paciente oncológico ao longo do desenvolvimento. Psicologia em estudo, 11(2), 361-369.

Brasil. 2011. Instituto Nacional de Câncer. O que é câncer? Rio de Janeiro, RJ: Ministério da Saúde.

Braz, A. 2016. Mulheres executivas transformam o mundo dos negócios. Disponível em: <http://www.antoniabraz.com.br/artigo.asp?id=95>. Acesso em: 12 out. 2019.

Cestari, E., \& Carlotto, M. S. 2012. Reabilitação profissional: o que pensa o trabalhador sobre sua reinserção. Estudos e Pesquisas em Psicologia, 12(1), 93-115.

Coelho, R. C. F. P. Qualidade de vida de mulheres com câncer de mama em tratamento quimioterápico adjuvante e neoadjuvante. Dissertação de Mestrado. Curitiba, PR: Universidade Federal do Paraná.

Costa Neto, S. B. D., \& Araújo, T. C. C. F. D. 2001. Avaliação da qualidade de vida em pacientes com câncer de cabeça e pescoço. Temas em Psicologia, 9(2), 125-135.

Feitosa, R. C. L., \& Pontes, E. R. J. C. 2011. Levantamento dos hábitos de vida e fatores associados à ocorrência de câncer de tabagistas do município de Sidrolândia (MS, Brasil). Ciência \& Saúde Coletiva, 16(2), 605-613.

Galvão, I. L. 2008. A mulher no mercado de trabalho. Disponivel em: <http//www.administradores.com.br/artigos/amulher-no-mercado-de-trabalho>. Acesso em: 23 out. 2019. 
Gomes, A. F. 2005. O outro no trabalho: mulher e gestão. REGE Revista de Gestão, 12(3), 1-9.

Hirata, H. (2014). Gênero, classe e raça Interseccionalidade e consubstancialidade das relações sociais. Tempo social, 26(1), 61-73.

Instituto Oncoguia. 2015. O que são genes? Disponível em: <http://www.oncoguia.org.br/conteudo/o-quesao-genes/8159/73/>. Acesso em: 12 out. 2019.

Instituto Brasileiro de Geografia e Estatística [IBGE]. 2010. Banco de dados agregados. Disponível em: http://www.ibge.gov.br/home/estatistica/indicadores/trabalhoerendimento/pme_nova/Mulher_Mercado_ Trabalho_Perg_Resp.pdf $>$. Acesso em: 24 out. 2019.

Imbuzeiro, S. A. 2015. Reflexões sobre As Relações Entre Trabalho Feminino, Dinâmica Familiar e Saúde da Mulher. São Luiz, MA.

Instituto de Pesquisa Econômica Aplicada [IPEA]. 2011. Retrato da desigualdade de gênero e raça (4a ed.). Brasília, DF: IPEA.

Kovács, M. J. 2002. Morrer com dignidade. In M. M. M. J. Carvalho (Org.), Introdução à Psiconcologia. Campinas, SP: Livro Pleno.

Machado, L. S. 2013. Igualdade de gênero: o papel da mulher no desenvolvimento sustentável da sociedade. Disponível em:<http://thebridgeglobal.org/blog/2019/09/19.

Mendes, K. D. S., Silveira, R. C. D. C. P., \& Galvão, C. M. 2008. Revisão integrativa: método de pesquisa para a incorporação de evidências na saúde e na enfermagem. Texto \& contexto-enfermagem, 17(4), 758-764.

Instituto Nacional do Câncer José Alencar Gomes da Silva [INCA]. 2018. Coordenaçãa de Prevenção e Vigilância/Divisão de Vigilância. Estimativa de Câncer no Brasil. Disponível em: <http://www.inca.gov.br/estimativa/2018/casos-brasil-consolidado.asp>. Acesso em: 18 out. 2019.

Muzart, Z. L. 2003. Uma espiada na imprensa das mulheres no século XIX. Revista Estudos Feministas, 11(1), 225.

Paulilo, M. I. S. 1987. O peso do trabalho leve. Revista Ciência Hoje, 5(28), 64-70.

Penna, T. L. M. 2004. Dinâmica psicossocial da família de pacientes com câncer. In J. Mello Filho, \& M. Burd. (Orgs.), Doença e família. São Paulo, SP: Casa do Psicólogo.

Prado, J. A. F. A. 2002. Supervivência: novos sentidos na vida após a mastectomia. Tese de Mestrado. SC: Universidade Federal de Santa Catarina.

Severino, A. J. 2007. Metodologia do Trabalho Científico. São Paulo, SP: Cortez.

Silva, A. C. L. F. 2008. Reflexões sobre o paradigma pós-moderno e os estudos históricos de gênero. BrathairRevista de Estudos Celtas e Germânicos, 8(2).

Silva, C. B., Albuquerque, V., \& Leite, J. 2010. Qualidade de vida em pacientes portadoras de neoplasia mamária submetidas a tratamentos quimioterápicos. Revista Brasileira de Cancerologia, 56(2), 227-36.

Silva. J. A. G. 2014. Instituto Nacional De Câncer. Estimativa 2014: incidência de câncer no Brasil. Rio de Janeiro, RJ: Inca.

Sina, A. 2005. Mulher e trabalho: o desafio de conciliar diferentes papéis na sociedade. São Paulo, SP: Editora Saraiva.

Smeltzer, S. C., Bare, B. G., Hinkle, J. L., \& Cheever, K. H. 2012. Brunner e Suddarth - Tratado de Enfermagem Médico-Cirúrgica (12a ed.). Rio de Janeiro, RJ: Guanabara Koogan.

Souza-Lobo, E. 1991. Mulheres: uma nova identidade. In Souza-Lobo, E. A classe operária tem dois sexos: trabalho, dominação e resistência. São Paulo, SP: Brasiliense.

Teixeira, L. C. 2009. Implicações subjetivas e sociais do câncer de boca: considerações psicanalíticas. Arquivos Brasileiros de Psicologia, 61(2), 1-12.

Torres, W. C. 2003. A bioética e a psicologia da saúde: reflexões sobre questões de vida e morte. Psicologia: reflexão e crítica, 16(3), 475-482.

Vasconcelos, A. D. S., Costa, C., \& Barbosa, L. N. F. 2008. Do transtorno de ansiedade ao câncer. Revista da SBPH, 11(2), 51-71.

Villar, R. R., Fernández, S. P., Garea, C. C., Pillado, M., Barreiro, V. B., \& Martín, C. G. 2017. Qualidade de vida e ansiedade em mulheres com câncer de mama antes e depois do tratamento. Revista Latino-Americana de Enfermagem, 25. 


\section{Minicurrículo}

Daniele Ramos Guedes. Mestranda do Curso de Gestão e Saúde Pública, Universidade Columbia Del Paraguai, Assistente Social do Município de Ferreira Gomes e Docente Instituto Macapaense de Melhor Ensino Superior, Macapá, Amapá, Brasil.

Glenda da Silva Coutinho Bacharel em Serviço Social, Instituto Macapaense de Melhor Ensino Superior, Macapá, Amapá, Brasil.

Josiana Alves Pimentel. Bacharel em Serviço Social, Instituto Macapaense de Melhor Ensino Superior, Macapá, Amapá, Brasil.

Como citar: Guedes, D.R., Coutinho, G.S., \& Pimentel, J.A. 2021. Mulheres que superaram o Câncer: À volta ao mercado de trabalho. Pubsaúde, 5, a114. DOI: https://dx.doi.org/10.31533/pubsaude5.a114

Recebido: 10 dez. 2020.

Revisado e aceito: $16 \mathrm{dez} .2020$.

Conflito de interesse: os autores declaram, em relação aos produtos e companhias descritos nesse artigo, não ter interesses associativos, comerciais, de propriedade ou financeiros que representem conflito de interesse.

Licenciamento: Este artigo é publicado na modalidade Acesso Aberto sob a licença Creative Commons Atribuição 4.0 (CC-BY 4.0). 